\title{
Influence of Sexually Degrading Music on Men's Perceptions of Women's Dating-Relevant Cues
}

\author{
TERESA A. TREAT ${ }^{1 *}$, COREEN A. FARRIS ${ }^{2}$, RICHARD J. VIKEN $^{3}$ and JODI R. SMITH ${ }^{1}$ \\ ${ }^{1}$ University of Iowa, Department of Psychology, Iowa City, USA \\ ${ }^{2}$ RAND Corporation, Pittsburgh, USA \\ ${ }^{3}$ Indiana University, Department of Psychological and Brain Sciences, Bloomington, USA
}

\begin{abstract}
Summary: This study examined the influence of manipulated and naturalistic exposure to sexually degrading music on young men's perceptions of women's dating-relevant affective cues. Three hundred ninety-seven undergraduate heterosexual men completed an affect-identification task in which they judged whether women communicated sexual interest, friendliness, sadness, or rejection. Either sexually degrading popular music, non-sexually degrading popular music, or no music played on headphones. Participants completed questionnaires assessing music-listening habits and rape-supportive attitudes. Manipulated exposure to degrading music did not affect men's sensitivities to or biases for women's cues. In contrast, men who reported greater naturalistic exposure to rap and hip-hop music and who endorsed more rape-supportive attitudes were more likely to perceive women's positive affect as sexual interest, if the women were provocatively dressed. On balance, these findings are largely inconsistent with theoretical expectations regarding the deleterious effects of sexually degrading music on attitudes and concurrent social perception. Copyright (C) 2014 John Wiley \& Sons, Ltd.
\end{abstract}

For young adults, decoding dating-relevant, nonverbal cues can be a difficult task fraught with opportunities for error and miscommunication. Discriminating friendliness from sexual interest may be a particularly challenging task, given overlap between the cues used to signal each (refer to Farris, Treat, Viken, \& McFall, 2008 for review). Sexual misperception is part of a constellation of risk factors that increases risk for sexually violent behavior (Abbey, Jacques-Tiura, \& LeBreton, 2011). Farris and colleagues found that inaccuracy of sexual perception among high-risk men relative to low-risk men was due to their relative insensitivity to women's affective cues (Farris, Viken, Treat, \& McFall, 2006; Farris, Viken, \& Treat, 2010b). Alcohol intoxication, women's revealing or provocative clothing, and attitudes that justify rape or blame victims for the assault have also been associated with lower sensitivity to women's nonverbal cues. Provocative clothing and alcohol intoxication also increase the tendency (or 'bias', in signal-detection theory terms) to perceive women's positive affect as indicating sexual interest rather than friendliness (Farris et al., 2006; Farris, Treat, \& Viken, 2010a; Farris et al., 2010b). Another contextual factor that has been hypothesized to prime sexual perception or behavior is music with sexually explicit or degrading lyrics, which is often present in typical dating contexts (e.g. bars, parties, and clubs).

There has been increasing concern about the potential impact of sexual content in contemporary music lyrics on sexual behavior (Council on Communications and Media, 2010). Primack, Gold, Schwarz, and Dalton (2008) found that $37 \%$ of popular songs contained sexually explicit lyrics. Of these, $65 \%$ were references to degrading sex. Weitzer and Kubrin (2009) found that $22 \%$ of the songs in best-selling rap albums contained lyrics that 'encourage, condone, or glorify the objectification, exploitation, or victimization of women',

*Correspondence to: Teresa A. Treat, Department of Psychology, University of Iowa, 11 Seashore Hall E, Iowa City, Iowa 52242, USA.

E-mail: teresa-treat@uiowa.edu
On average, high school students listen to $15 \mathrm{~h}$ of music with sexually degrading lyrics each week (Primack, Douglas, Fine, \& Dalton, 2009). Naturalistic exposure to sexually degrading music content correlates positively with the likelihood of sexual debut (Martino et al., 2006), while naturalistic exposure to non-degrading sexual content does not (refer also to Primack et al., 2009). If observing social behavior is indeed a powerful influence on one's own behavior, as argued by Bandura (2002), exposure to sexually degrading content could increase negative attitudes toward women, acceptance of aggression, and risk for sexual coercion or aggression.

Results of studies examining the effects of manipulated exposure to musical content have been mixed. Relative to songs without degrading content, manipulated exposure to songs with sexually degrading or misogynous content increases adversarial sexual beliefs but shows no effect on other negative attitudes toward women (e.g. Cobb \& Boettcher, 2007; Sprankle \& End, 2009). St. Lawrence and Joyner (1991) showed that, relative to participants who were assigned to listen to classical music, participants who were assigned to listen to sexually violent heavy metal music were more likely to endorse items measuring sex-role stereotyping. However, this effect was the same for heavy metal music with religious lyrics rather than sexually violent lyrics, suggesting that musical genre rather than lyrical themes may have produced the effect on sex-role stereotyping. Fischer and Greitemeyer (2006) found that participants who listened to popular music with misogynous lyrics generated more negative attitudes toward women than did participants who listened to popular music with neutral lyrics.

Regarding more behavioral outcomes, Fischer and Greitemeyer (2006) found that men who first were exposed to misogynous lyrics subsequently assigned significantly longer (potentially painful) consequences to a female confederate than men exposed to non-misogynous lyrics. Barongan and Hall (1995) found that undergraduate men who listened to misogynous rap songs were more likely to expose female confederates to violent video clips than men 
who listened to rap songs with lyrics advocating social justice. More generally, manipulated exposure to songs with aggressive lyrics has been linked to increased state anger and analogue aggression (Anderson, Carnagey, \& Eubanks, 2003; Brummert, Lennings \& Warburton, 2011). Conversely, exposure to prosocial lyrics has been found to increase accessibility of prosocial words and the expression of prosocial behavior (e.g. Greitemeyer, 2011).

Despite a developing literature on the effects of sexually degrading lyrics on attitudes and behavior, there has been no work to examine the influence on social perception, and in particular, men's perception of women's affect and sexual intent. Basic social perception processes, such as inferences about women's emotions, may lie upstream from some of the observed effects on attitudes and behavior and may help to explain the findings. Thus, this study is designed to examine the influence of both manipulated and naturalistic exposure to sexually degrading lyrics on young men's perception of women's dating-relevant affect. Because men often judge women's affect in dating-relevant contexts while music plays in the background, we assessed social perception while music played simultaneously. To decrease the likelihood of confounding by tempo, musical genre, or the characteristics of individual songs or musicians, lyric content (sexually degrading versus non-degrading) was carefully manipulated by selecting a relatively large set of contemporary songs, performed by male artists, matched by artist and tempo across themes, and selected via reliable coding of lyrical content.

We used a well-established social perception task in which men judge whether women depicted in full-body photographs are communicating sexual interest, friendliness, sadness, or rejection (Farris et al., 2006, 2008; refer also to Farris et al., 2010a; Farris et al., 2010b). This task allows us to parse the source of observed affect-identification errors into perceptual sensitivity (the ability to discriminate between women's affective states) and decisional bias (a tendency to respond that women's affect reflects a given category, such as sexual interest). Models that allow precision of this sort are part of a general movement to use methods derived from cognitive science in order to be more quantitative and theoretically explicit about socially and clinically relevant processes (e.g. Treat et al., 2007). Decomposing the source of observed errors also may provide more precise intervention and prevention targets.

\section{METHOD}

\section{Participants}

Participants were 349 undergraduate heterosexual or bisexual men with complete data. Their average age was 19.45 years $(S D=2.55)$, and the sample was predominately Caucasian $(80.3 \%)$. The majority of participants reported some dating $(91.7 \%)$ and sexual experience $(81.4 \%$, oral or vaginal intercourse).

\section{Materials}

Playlists

Eight songs, performed by a male vocalist, with lyrics that were degrading toward women, were selected for the degrading music condition. Each song in the degrading condition was matched to a song performed by the same vocalist but with lyrics that were not degrading toward women, to form the non-degrading set list. In order to develop an externally valid set of music with songs that a young adult population might hear at parties, clubs or on the radio, we selected 108 songs (55 possibly degrading, 53 possibly nondegrading) that had appeared on Billboard's Hot 100 list in the prior 2 years.

Three of the four authors reviewed the lyrics of each song and rated 'how degrading toward women are the lyrics?' on a scale from ' 0 ' (not at all) to ' 10 ' (extremely). 'Degrading toward women' was defined as lyrics that were demeaning, were sexually objectifying, described women as property, or described threatened or actual violence toward women. Inter-rater reliability was good $(\mathrm{ICC}=0.82)$. The final set of eight degrading and eight vocalist-matched, nondegrading songs were selected via the following criteria: (1) degrading songs with an average rating $\geq 7$, (2) matched non-degrading songs with an average rating $\leq 3$, and (3) no more than two songs by the same artist.

As expected, lyrics in the degrading music set were rated as more degrading $(8.83, S D=0.80)$ than lyrics in the nondegrading music set $(0.67, S D=0.78), t(7)=17.17, p<.001$. To ensure that the overall energy of each set list was balanced, we confirmed that the average song tempo (beats per minute) did not vary across the lists, $t(7)=-0.083$, $p=.936$. Participants reported that they were familiar with $(M=4.48, \quad S D=1.40, \quad$ on a 7-point scale) and liked $(M=3.96, S D=1.30)$ the songs and that the songs were similar to the music to which they normally listened $(M=3.94$, $S D=1.54)$. Seven of eight songs in each group were rap/hip-hop or R\&B, with the remaining song being rock/pop. Four quasi-random set lists were developed for the degrading condition, and four matching non-degrading sets were created by yoking songs by the same male vocalist.

\section{Women's affect stimulus set}

Stimuli were a set of 280 full-body photographs of women displaying one of four dating-relevant emotions (friendly, sexually interested, sad, rejecting) and wearing clothing varying in sexual provocativeness (refer to Farris et al., 2006).

\section{Identification task}

Participants categorized each image into one of four categories based on the nonverbal cues they perceived the women to be displaying. Images were presented in a random order for $1000 \mathrm{~ms}$ each, after which participants indicated if the woman was (1) friendly, (2) sexually interested, (3) sad, or (4) rejecting.

\section{Measures}

Illinois Rape Myth Acceptance Scale (IRMA)

The IRMA (Payne, Lonsway, \& Fitzgerald, 1999) assesses endorsement of rape-supportive attitudes, a well-established correlate of self-reported perpetration of sexual coercion and aggression (e.g. Murnen, Wright, \& Kaluzny, 2002). 


\section{Music questionnaire}

Participants in a music condition reported how well they could hear and how much they enjoyed the music selection on a 7-point scale; participants reported hearing the music very well $(M=6.81, S D=.47)$. They also reported how many hours per week on average they spent listening to each of four musical genres: rap and hip-hop, $\mathrm{R} \& \mathrm{~B}$, country, and pop (top 40). Average reported listening time to rap and hip-hop music $(M=6.69, S D=9.92)$ served as our naturalistic exposure index in all analyses, given that most songs in both music conditions were rap and hip-hop and that Primack et al. (2008) found that popular songs that referenced degrading sex were most commonly rap. The last 44 participants in a music condition were asked how well they could understand the words the artist was singing on a 7 -point scale $(1=$ not at all; $7=$ extremely well). Mean ratings were $5.33(S D=1.59)$ and $4.74(S D=1.84)$ for those in the degrading and non-degrading conditions, respectively.

\section{Music clip ratings}

Based on brief song clips in the music conditions, participants judged their familiarity with the song, the similarity of the song to the music to which they normally listened, and how much they liked the song on 7-point scales.

\section{Demographics questionnaire}

Participants reported their race/ethnicity, marital status, age, and sexual orientation.

\section{Procedure}

Participants completed the identification task in a private testing cubicle after being told whether they would be listening to music or not during the task. Participants were instructed that they could turn down or turn off the music if they found it disturbing. Participants then completed the Music Questionnaire, the Music Clip Ratings, the IRMA, and the Demographics Questionnaire. Participants were compensated with course credit.

\section{Analytic approach}

Choice theory parameters, sensitivity and bias (or threshold), were estimated for each participant individually (refer to Farris et al., 2006 for details on our computational approach, which is based on Luce, 1959 and Macmillan \& Creelman, 2004). The sensitivity parameter provides a quantitative estimate of an observer's ability to perceptually distinguish between cues. The bias parameter quantifies an observer's response preference or decision threshold. For identification tasks with more than two response cues, bias can be computed as a ratio between two response tendencies (Macmillan \& Creelman, 2004). We chose to examine the theoretically relevant pairs of friendly versus sexually interested (positive affect) and sad versus rejecting (negative affect). Sexualinterest threshold refers to the category boundary between friendliness and sexual interest, which becomes higher, or more conservative, as fewer women are classified as sexually interested and lower, or more liberal, as more women are classified as sexually interested. The second estimate captures the rejection threshold or the category boundary between sadness and rejection. Higher values indicate a higher threshold for rejection, such that fewer women are rejecting, and lower values indicate a lower threshold for rejection, such that more women are perceived to be rejecting.

\section{RESULTS}

A generalized estimating equation (GEE) model was used to examine five influences on participants' sensitivity indices: affect (sexually interested, friendly, sad, or rejecting); provocativeness of dress (POD; high or low); music condition (degrading, non-degrading, no music); endorsement of rape-supportive attitudes (IRMA; centered); and music exposure (number of hours listen to rap/hip-hop each week, logtransformed and centered). The model included main effects and all interactions among the experimental factors (affect, POD, and condition) and main effects and all two-way and three-way interactions involving the covariates (IRMA and music exposure).

Several effects were consistent with prior research using this identification paradigm (Farris et al., 2006, 2008). First, affect exerted a large influence on men's sensitivity to women's dating-relevant cues, Wald $\chi^{2}(3)=890.27$, $p<.001$. Men's sensitivity to friendliness $(M=2.25)$ greatly exceeded their sensitivity to sexual interest, sadness, and rejection $(M s=1.42,1.56,1.49 ; d s=1.23,1.37,1.35)$. Second, men showed greater sensitivity to women's affect when the women were dressed conservatively $(M=1.71)$ rather than provocatively $(M=1.66), \quad d=.29$, Wald $\chi^{2}(1)=26.09$, $p<.001$. Third, a large interaction between affect and POD emerged, Wald $\chi^{2}(3)=407.67, p<.001$. Men showed greater sensitivity to sexual interest when women dressed provocatively $(M=1.56$ vs $M=1.28, d=.59)$, greater sensitivity to sadness and rejection when women dressed conservatively $(M=1.72$ vs $M=1.40, d=.92 ; \quad M=1.58$ vs $M=1.41$, $d=.49)$. These three replication effects are depicted in Figure 1. Fourth, POD interacted with endorsement of rapesupportive attitudes (IRMA) in predicting sensitivity, Wald $\chi^{2}(1)=5.41, p<.05$. Follow-up analyses revealed a slightly larger IRMA effect when POD was conservative, rather than provocative, Wald $\chi^{2}(1)=13.62$ vs $10.09, p<.01, q=-.04$. Finally, IRMA also correlated moderately negatively with men's sensitivities, as in past research, Wald $\chi^{2}(1)=14.79$, $p<.001, r=-.29$.

The main effect of condition on sensitivity was small and unreliable, Wald $\chi^{2}(2)=0.89$. Condition did not interact reliably with any of the other factors or covariates in predicting sensitivity.

Music exposure showed a reliable interaction with IRMA, Wald $\chi^{2}(1)=4.46, p<.05$, such that the IRMA-sensitivity correlation was near zero for those with higher exposure but became negative as exposure decreased, $q$ (for difference in IRMA-sensitivity correlations for those listening to more versus less than average rap and hip-hop music) $=-.39$.

GEE models were used to examine effects of POD, music condition, IRMA, and music exposure on participants' thresholds for judging sexual interest and rejection. The model included main effects and the interaction between the experimental factors (POD and condition) and main 


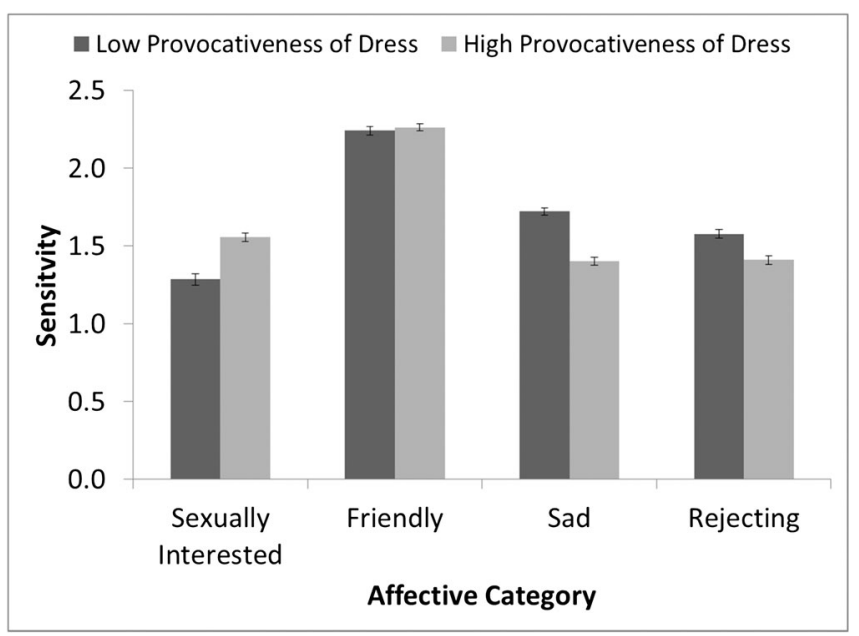

Figure 1. Interactive influence of affect and clothing style on men's sensitivity to women's dating-relevant cues

effects and all two-way and three-way interactions involving the covariates (IRMA and music exposure).

The moderately strong effect of POD on men's sexualinterest threshold replicated past work, Wald $\chi^{2}(1)=127.541$, $p<.001$. Men classified relatively more women as sexually interested when the women were dressed provocatively $(M=.61)$ rather than conservatively $(M=.99), d=.59$. The effect of POD on men's sexual-interest threshold was moderated by endorsement of rape-supportive attitudes, Wald $\chi^{2}(1)=14.684, p<.001$, as in prior work; IRMA predicted the threshold only when POD was high, Wald $\chi^{2}(1)=7.936$, $p<.01$, rather than low, Wald $\chi^{2}(1)=.015$, n.s. The interaction between POD and IRMA also was moderated by music exposure, Wald $\chi^{2}(1)=9.348, p<.01$. Figure 2 illustrates this effect. As music exposure increases, the observed interaction between IRMA and POD strengthens, such that men's sexual-interest threshold for provocatively dressed women declines even more sharply when participants both endorse rape-supportive attitudes and report greater exposure to rap and hip-hop music. An alternative interpretation of the three-way interaction indicates that IRMA and music exposure are largely unrelated to men's sexual-interest threshold when women are dressed conservatively. When women are dressed provocatively, however, higher risk men show a much lower threshold for detecting sexual interest if their reported music exposure is in the upper quartile rather than the lowest quartile, $d=.939$.

The effect of music condition on men's sexual-interest threshold was unreliable, Wald $\chi^{2}(2)=5.361$, n.s. Condition also did not interact reliably with any of the other factors or covariates in predicting the sexual-interest threshold.

No reliable predictors emerged for men's rejection threshold.

\section{DISCUSSION}

The current work evaluated the influence of both manipulated and naturalistic exposure to popular misogynistic music, as well as endorsement of rape-supportive attitudes, on men's perceptions of women's dating-relevant affect. Choice-model analyses allowed us to quantify for each participant both sensitivity indices for four affective cues and two bias parameters that indexed thresholds for perceiving sexual interest and rejection.

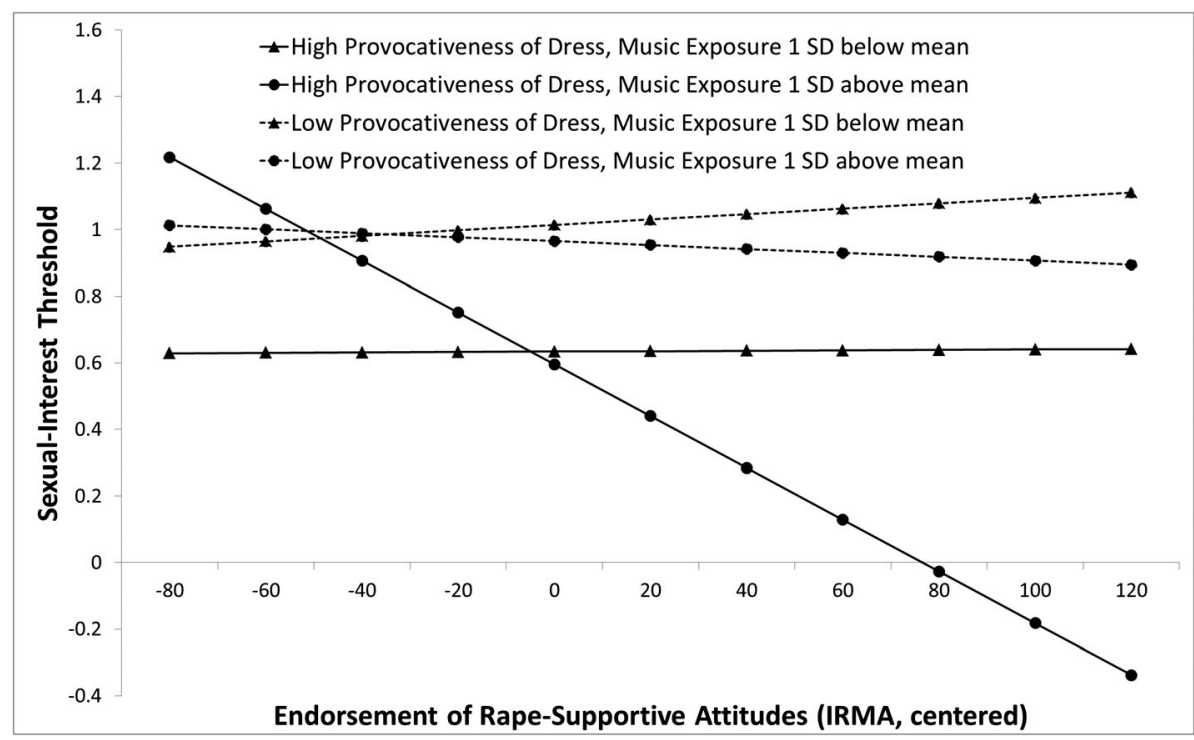

Figure 2. Interactive influence of provocativeness of dress, endorsement of rape-supportive attitudes, and naturalistic exposure to rap and hiphop music on threshold for judging women's sexual interest 


\section{Replicated influences on affect-identification processes}

Overall, the current study strongly replicated prior findings with the affect-identification paradigm (refer to Farris et al., 2006, 2008, 2010b). Sensitivity for friendliness was sharply higher than sensitivity for the other three categories, and sensitivity overall was greater when women dressed conservatively rather than provocatively. Participants also showed moderately greater sensitivity when clothing style was 'congruent' with the affect category. Figure 1 illustrates these effects. Endorsement of rape-supportive attitudes again predicted lower sensitivity to affect, particularly when clothing style was conservative. Participants perceived more women to be expressing sexual interest when the women dressed provocatively, rather than conservatively. Clothing style also again interacted with endorsement of rape-supportive attitudes, whereby high-risk men's interpretations of women's sexual interest showed greater conflation with women's clothing style.

Overall, these findings further strengthen our confidence in concluding that (a) type of affect and clothing style influence men's processing of women's dating-relevant affective cues and (b) at-risk men show impoverished identification of women's affective cues and greater influence by nonaffective contextual factors like clothing style (Farris et al., 2006, 2008; Farris et al., 2010a; Farris et al., 2010b; refer also to Treat, McFall, Viken, \& Kruschke, 2001; Treat, Viken, Kruschke, \& McFall, 2011; Treat, Viken, Farris, \& Smith, under review). Furthermore, both the comparability of average sensitivity scores and the consistency of the current results with prior findings underscore the validity of the identification task in the presence of the music manipulation.

\section{Manipulated exposure to degrading music}

Exposure to degrading music neither decreased college men's sensitivity to women's affect nor decreased their threshold for perception of sexual interest. Endorsement of rape-supportive attitudes also did not moderate the effect of music condition on sensitivity or sexual-interest threshold, suggesting that manipulated exposure did not influence social perception even among those presumably more vulnerable to exposure. Finally, manipulated exposure to sexually degrading lyrics did not increase endorsement of negative attitudes toward women.

These findings are inconsistent with theoretical perspectives suggesting that exposure to sexually explicit and degrading media produces harmful effects on sexual attitudes and behaviors, either for everyone or for those assumed to be most vulnerable to media effects (e.g. Anderson et al., 2003; Fischer, Greitemeyer, Kastenmüller, Vogrincic, \& Sauer, 2011). The relevant empirical literature is mixed with respect to attitudinal effects, but the two studies examining a behavioral analogue to aggression both documented the theoretically expected effects (Barongan \& Hall, 1995; Fischer \& Greitemeyer, 2006). Of course, the current work focused primarily on the effects of exposure to misogynistic music on social perception, rather than on an analogue measure of aggression toward women. Impoverished processing of women's affective cues has been linked to sexual coercion and aggression both theoretically and empirically, however (refer to Farris et al., 2008 and Abbey et al., 2011, for reviews), making it an important phenomenon to investigate. We were sufficiently powered to detect effects that were small to moderate in magnitude (i.e. power of .84 to detect an effect as small as $f=.20$ ), so if there were substantial effects of music exposure on social perception, we should have been able to detect them.

Participants in our study listened to music while concurrently completing the affect-identification task, whereas manipulated music exposure in prior work has occurred prior to the assessment of sexual attitudes or behavior, and participants typically have been encouraged to focus on the music and lyrics. Thus, it is possible that affect identification interfered with listening to music. However, dual task designs have repeatedly demonstrated effects of music on perception and cognition more broadly (e.g. Jeffries, Smilek, Eich, \& Enns, 2008; McConnell \& Shore, 2011), and music and sexual perception are likely to be concurrent in the naturalistic environment.

The current manipulated 'dose' of approximately $20 \mathrm{~min}$ of music exceeded that of all relevant experimental studies in the literature, to our knowledge, and thus should have been sufficient to produce the hypothesized attitudinal, social-perceptual, and behavioral effects. Higher doses would be logistically challenging to implement on an experimental basis, but the association of naturalistic exposure to rap and hip-hop music with both social perception and attitudes toward women provides a window onto this issue.

\section{Naturalistic exposure to rap and hip-hop music}

We examined the number of hours per week that participants reported listening to rap and hip-hop music as an indicator of naturalistic exposure to sexually degrading music. Naturalistic exposure was not associated reliably with either sensitivity to affect or the sexual-interest threshold, except in interaction with endorsement of rape-supportive attitudes. Among men reporting higher naturalistic exposure, no association emerged between attitudes and sensitivity to affect. Among men reporting lower naturalistic exposure, however, greater endorsement of rape-supportive attitudes was associated with moderately reduced sensitivity to affect. Thus, the presence of negative attitudes toward women mattered more when other factors, such as high naturalistic exposure to rap and hip-hop music, were absent.

Naturalistic exposure also reliably moderated the interaction between clothing style and rape-supportive attitudes on the sexual-interest threshold. Men who endorsed more rape-supportive attitudes and reported greater naturalistic exposure to rap and hip-hop music showed lower thresholds when women dressed provocatively, such that more women were judged to be sexually interested. Overall, men's threshold for sexual interest dropped when the woman was provocatively dressed, dropped further for high-risk men viewing provocatively dressed women, and dropped further still for high-risk men with higher naturalistic exposure to rap and hip-hop music viewing provocatively dressed women. In contrast, when women were dressed conservatively, neither attitudes nor naturalistic music exposure were linked to 
sexual-interest threshold. Both theoretical and empirical work indicates that men with more liberal thresholds for perception of the sexual interest of provocatively dressed women are at greater risk of exhibiting sexually aggressive behavior (Farris et al., 2006, 2010b). Thus, the link between naturalistic exposure to rap/hip-hop music and sexual-interest thresholds for provocatively dressed women among those men who may be more vulnerable to the effects of the music is concerning.

Future research will be necessary to determine the extent to which this intriguing three-way interaction reflects direct effects of music exposure on perception or selection effects (e.g. men with particular characteristics also choose to listen to more rap and hip-hop). Resolution of these issues ultimately will necessitate experimental work with larger doses, as well as longitudinal research that examines the way in which sexual-perception processes, music exposure, rape-supportive attitudes, and other risk factors for sexual aggression unfold over time.

\section{CONCLUSIONS}

Overall, the current work indicates that brief manipulated exposure to degrading music neither reduces men's sensitivity to women's affective cues nor lowers the threshold for perception of women's sexual interest. In contrast, men who both reported greater naturalistic exposure to rap/hip-hop music and endorsed more misogynistic attitudes were more likely than other men to perceive women's positive affective responses as sexual interest, if the women were provocatively dressed. Thus, it was the confluence of multiple individual differences in men and the contextual variable of women's dress that determined differences in perception. On balance, these findings are largely inconsistent with theoretical expectations regarding the deleterious effects of sexually degrading music on attitudes and concurrent social perception. Future research might profitably explore differences between (a) the concurrent listening and the social perception procedures used in this study; and (b) the sequential listening with reflection followed by behavioral assessments used in most past research. Although the concurrent assessment approach probably better matches real world music contexts for undergraduate men, it is possible that more robust effects of degrading music on attitudes, perceptions, and behavior depend on longer and more reflective music listening in the laboratory.

Notably, the null results for music exposure occurred in the context of strong and consistent replications of past results regarding the relative difficulty for young men of judging different affective responses from women; the effects of women's clothing style on men's perceptions of affect; and the associations between men's misogynistic attitudes, their perceptions, and their susceptibility to the influence of clothing style. In the current data, at least, all of these factors were stronger and more consistent predictors of social perception than exposure to degrading music. Overall, this work illustrates the value of using performance-based computational models from cognitive science to foster understanding of putative effects on social perception, as well as the importance of considering interactions across contextual, perceptual, and dispositional levels of analysis.

\section{REFERENCES}

Abbey, A., Jacques-Tiura, A. J., \& LeBreton, J. M. (2011). Risk factors for sexual aggression in young men: An expansion of the confluence model. Aggressive Behavior, 37, 450-464.

Anderson, C. A., Carnagey, N. L., \& Eubanks, J. (2003). Exposure to violent media: The effects of songs with violent lyrics on aggressive thoughts and feelings. Journal of Personality and Social Psychology, 84, 960-971.

Bandura, A. (2002). Social cognitive theory of mass communication. In J. Bryant \& D. Zillman (Eds.), Media effects: Advance in theory and research ( $2^{\text {nd }}$ ed., pp. 121-154). Mahwah, NJ: Erlbaum.

Barongan, C., \& Hall, G. C. N. (1995). The influence of misogynous rap music on sexual aggression against women. Psychology of Women Quarterly, 19, 195-207.

Brummert Lennings, H. I., \& Warburton, W. A. (2011). The effect of auditory versus visual violent media exposure on aggressive behaviour: The role of song lyrics, video clips and musical tone. Journal of Experimental Social Psychology, 47, 794-799.

Cobb, M. D., \& Boettcher III, W. A. (2007). Ambivalent sexism and misogynistic rap music: Does exposure to Eminem increase sexism? Journal of Applied Social Psychology, 37, 3025-3042.

Council on Communications and Media (2010). Sexuality, contraception, and the media. Pediatrics, 126, 576-582.

Farris, C., Viken, R., Treat, T., \& McFall, R. (2006). Heterosocial perceptual organization: Application of the choice model to sexual coercion. Psychological Science, 17, 869-875.

Farris, C., Treat, T. A., Viken, R. J., \& McFall, R. M. (2008). Sexual coercion and the misperception of sexual intent. Clinical Psychology Review, $28,48-66$.

Farris, C., Treat, T. A., \& Viken, R. J. (2010a). Alcohol alters men's perceptual and decisional processing of women's sexual interest. Journal of Abnormal Psychology, 119, 427-432.

Farris, C., Viken, R. J., \& Treat, T. A. (2010b). Perceived association between diagnostic and non-diagnostic cues of women's sexual interest: General Recognition Theory predictors of risk for sexual coercion. Journal of Mathematical Psychology, 54, 137-149.

Fischer, P., \& Greitemeyer, T. (2006). Music and aggression: The impact of sexual-aggressive song lyrics on aggression-related thoughts, emotions, and behavior toward the same and opposite sex. Personality and Social Psychology Bulletin, 32, 1165-1176.

Fischer, P., Greitemeyer, T., Kastenmüller, A., Vogrincic, C., \& Sauer, A. (2011). The effects of risk-glorifying media exposure on risk-positive cognitions, emotions, and behaviors: A meta-analytic review. Psychological Bulletin, 137, 367-390.

Greitemeyer, T. (2011). Exposure to music with prosocial lyrics reduces aggression: First evidence and test of the underlying mechanism. Journal of Experimental Social Psychology, 47, 28-36.

Jeffries, L. N., Smilek, D., Eich, E., \& Enns, J. T. (2008). Emotional valence and arousal interact in attentional control. Psychological Science, 19, 290-295.

Luce, R. D. (1959). Individual choice behavior. New York: Wiley.

Macmillan, N. A., \& Creelman, C. D. (2004). Detection theory: A user's guide. NewYork: Cambridge University Press.

Martino, S. C., Collins, R. L., Elliott, M. N., Strachman, A., Kanouse, D. E., \& Berry, S. H. (2006). Exposure to degrading versus nondegrading music lyrics and sexual behavior among youth. Pediatrics, 118, e430-e441.

McConnell, M. M., \& Shore, D. I. (2011). Upbeat and happy: Arousal as an important factor in studying attention. Cognition and Emotion, 25, 1184-1195.

Murnen, S. K., Wright, C., \& Kaluzny, G. (2002). If "boys will be boys," then girls will be victims? A meta-analytic review of the research that relates masculine ideology to sexual aggression. Sex Roles, 46, 359-375.

Payne, D. L., Lonsway, K. A., \& Fitzgerald, L. F. (1999). Rape myth acceptance: Exploration of its structure and its measurement using the Illinois Rape Myth Acceptance Scale. Journal of Research in Personality, 33, 27-68.

Primack, B. A., Douglas, E. L., Fine, M. J., \& Dalton, M. A. (2009). Exposure to sexual lyrics and sexual experience among urban adolescents. American Journal of Preventative Medicine, 36, 317-323. 
Primack, B. A., Gold, M. A., Schwarz, E. B., \& Dalton, M. A. (2008). Degrading and non-degrading sex in popular music: A content analysis. Public Health Reports, 123, 593-600.

Sprankle, E. L., \& End, C. M. (2009). The effects of censored and uncensored sexually explicit music on sexual attitudes and perceptions of sexual activity. Journal of Media Psychology, 21, 60-68.

St. Lawrence, J. S., \& Joyner, D. J. (1991). The effects of sexually violent rock music on males' acceptance of violence against women. Psychology of Women Quarterly, 15, 49-63.

Treat, T. A., McFall, R. M., Viken, R. J., \& Kruschke, J. K. (2001). Using cognitive science methods to assess the role of social information processing in sexually coercive behavior. Psychological Assessment, $13,549-565$.
Treat, T. A., McFall, R. M., Viken, R. J., Kruschke, J. K., Nosofsky, R. M., \& Wang, S. S. (2007). Clinical-cognitive science: Applying quantitative models of cognitive processing to examination of cognitive aspects of psychopathology. In R.W.J. Neufeld (Ed.), Advances in clinicalcognitive science: Formal modeling and assessment of processes and symptoms (pp. 179-205). Washington DC: APA Books.

Treat, T. A., Viken, R. J., Kruschke, J. K., \& McFall, R. M. (2011). Men's memory for women's affective cues: Normative findings and links to rapesupportive attitudes. Journal of Applied Cognitive Psychology, 25, 802-810.

Treat, T. A., Viken, R. J., Farris, C. A., \& Smith, J. R. (under review). Enhancing men's perceptions of women's sexual interest.

Weitzer, R., \& Kubrin, C. E. (2009). Misogyny in rap music: A content analysis of prevalence and meanings. Men and Masculinities, 12, 3-29. 